Louisiana State University

LSU Digital Commons

3-28-2011

\title{
Direct measurements of field-induced adiabatic temperature changes near compound phase transitions in Ni-Mn-In based Heusler alloys
}

\author{
A. P. Kazakov \\ Lomonosov Moscow State University \\ V. N. Prudnikov \\ Lomonosov Moscow State University
}

A. B. Granovsky

Lomonosov Moscow State University

A. P. Zhukov

Universidad del Pais Vasco

J. Gonzalez

Universidad del Pais Vasco

See next page for additional authors

Follow this and additional works at: https://digitalcommons.Isu.edu/physics_astronomy_pubs

\section{Recommended Citation}

Kazakov, A., Prudnikov, V., Granovsky, A., Zhukov, A., Gonzalez, J., Dubenko, I., Pathak, A., Stadler, S., \& Ali, N. (2011). Direct measurements of field-induced adiabatic temperature changes near compound phase transitions in Ni-Mn-In based Heusler alloys. Applied Physics Letters, 98 (13) https://doi.org/10.1063/ 1.3574088

This Article is brought to you for free and open access by the Department of Physics \& Astronomy at LSU Digital Commons. It has been accepted for inclusion in Faculty Publications by an authorized administrator of LSU Digital Commons. For more information, please contact ir@lsu.edu. 


\section{Authors}

A. P. Kazakov, V. N. Prudnikov, A. B. Granovsky, A. P. Zhukov, J. Gonzalez, I. Dubenko, A. K. Pathak, S. Stadler, and N. Ali 
Southern Illinois University Carbondale

OpenSIUC

Publications

Department of Physics

3-2011

Direct Measurements of Field-Induced Adiabatic Temperature Changes Near Compound Phase Transitions in Ni-Mn-In Based Heusler Alloys

A. P. Kazakov

Moscow State University

V. N. Prudnikov

Moscow State University

A. B. Granovsky

Moscow State University

A. P.Zhukov

Basque Country University

J. Gonzalez

Basque Country University

See next page for additional authors

Follow this and additional works at: http://opensiuc.lib.siu.edu/phys_pubs

(C) 2011 American Institute of Physics

Published in Applied Physics Letters, Vol. 98 No. 13 (2011) at doi: 10.1063/1.3574088

\section{Recommended Citation}

Kazakov, A. P., Prudnikov, V. N., Granovsky, A. B., Zhukov, A. P., Gonzalez, J., Dubenko, I., Pathak, A. K., Stadler, S. and Ali, N.. "Direct Measurements of Field-Induced Adiabatic Temperature Changes Near Compound Phase Transitions in Ni-Mn-In Based Heusler Alloys." (Mar 2011).

This Article is brought to you for free and open access by the Department of Physics at OpenSIUC. It has been accepted for inclusion in Publications by an authorized administrator of OpenSIUC. For more information, please contact opensiuc@lib.siu.edu. 
Authors

A. P. Kazakov, V. N. Prudnikov, A. B. Granovsky, A. P. Zhukov, J. Gonzalez, I. Dubenko, A. K. Pathak, S. Stadler, and N. Ali 


\title{
Direct measurements of field-induced adiabatic temperature changes near compound phase transitions in $\mathrm{Ni}-\mathrm{Mn}$-In based Heusler alloys
}

\author{
A. P. Kazakov, ${ }^{1}$ V. N. Prudnikov, ${ }^{1}$ A. B. Granovsky, ${ }^{1}$ A. P. Zhukov, ${ }^{2}$ J. Gonzalez, ${ }^{2}$ \\ I. Dubenko, ${ }^{3, a)}$ A. K. Pathak, ${ }^{3}$ S. Stadler, ${ }^{4}$ and N. Ali ${ }^{3}$ \\ ${ }^{1}$ Faculty of Physics, Moscow State University, Moscow 119991, Russia \\ ${ }^{2}$ Faculty of Chemistry, Basque Country University, San Sebastian 20080, Spain \\ ${ }^{3}$ Department of Physics, Southern Illinois University, Carbondale, Illinois 62901, USA \\ ${ }^{4}$ Department of Physics and Astronomy, Louisiana State University, Baton Rouge, Louisiana 70803, USA
}

(Received 29 January 2011; accepted 14 March 2011; published online 31 March 2011)

\begin{abstract}
The adiabatic temperature changes $\left(\Delta \mathrm{T}_{\mathrm{ad}}\right)$ in the vicinity of the Curie and martensitic transition temperatures of $\mathrm{Ni}_{50} \mathrm{Mn}_{35} \mathrm{In}_{15}$ and $\mathrm{Ni}_{50} \mathrm{Mn}_{35} \mathrm{In}_{14} \mathrm{Z}(\mathrm{Z}=\mathrm{Al}$ and $\mathrm{Ge}$ ) Heusler alloys have been studied using an adiabatic magnetocalorimeter of $250-350 \mathrm{~K}$ temperature interval for applied magnetic field changes up to $\Delta \mathrm{H}=1.8 \mathrm{~T}$. The largest measured changes were $\Delta \mathrm{T}_{\mathrm{ad}}=-2$ and $2 \mathrm{~K}$ near the martensitic (first-order) and ferromagnetic (second-order) transitions for $\Delta \mathrm{H}=1.8 \mathrm{~T}$, respectively. It was observed that $\left|\Delta \mathrm{T}_{\mathrm{ad}}\right| \approx 1 \mathrm{~K}$ for relatively small field changes $(\Delta \mathrm{H}=1 \mathrm{~T})$ for both types of transitions. The results indicate that these materials should be further explored as potential working materials in magnetic refrigeration applications. (C) 2011 American Institute of Physics.

[doi:10.1063/1.3574088]
\end{abstract}

The magnetic materials that exhibit large magnetocaloric effects (MCEs), i.e., the ability to absorb or produce heat as the result of the application of external magnetic fields $(\mathrm{H})$, are of significant interest because of their potential impact for application in environmentally friendly refrigeration devices. ${ }^{1}$ The MCE originates from the change in magnetization induced by the magnetic field, and characterized by a change in magnetic entropy and, therefore, in the temperature of the sample. Magnetic systems that undergo fieldinduced phase transitions, characterized by large, sharp changes in magnetization near or above room temperature, are of considerable interest as promising MCE materials. One such system is the off-stoichiometric $\mathrm{Ni}_{50} \mathrm{Mn}_{50-\mathrm{x}} \mathrm{In}_{\mathrm{x}}$ Heusler alloys. It has been found that these compounds, with concentrations in vicinity of $x=15$, demonstrate a specific type of structural instability known as a martensitic transformation. This instability is described as a temperature-induced first-order structural phase transition (at $\mathrm{T}_{\mathrm{M}}$ ) from a hightemperature austenitic phase (AP) with cubic $\mathrm{L}_{1}$ or $\mathrm{B}_{2}$ crystal structure, to a low-temperature martensitic phase (MP) (or inverse transition at $\mathrm{T}_{\mathrm{A}}$ ), characterized by a crystal cell of lower symmetry (tetragonal, tetragonal modulated, orthorhombic, or monoclinic). ${ }^{2}$ In most cases, the AP is ferromagnetically ordered below $T_{C}$, and $T_{C}$ is greater than $T_{A}$ and $\mathrm{T}_{\mathrm{M}}$. At least four magnetic phases can be detected in the compounds; (i) a low temperature ferromagnetic MP (below $\left.\mathrm{T}_{\mathrm{CM}}\right)$, (ii) an antiferromagnetic/paramagnetic $\mathrm{MP}\left(\mathrm{T}_{\mathrm{CM}}<\mathrm{T}\right.$ $<\mathrm{T}_{\mathrm{M}}$ ), (iii) a ferromagnetic $\mathrm{AP}\left(\mathrm{T}_{\mathrm{M}}<\mathrm{T}<\mathrm{T}_{\mathrm{C}}\right)$, and (iv) a high temperature paramagnetic AP $\left(\mathrm{T}_{\mathrm{C}}<\mathrm{T}\right)$ [see, for example, Ref. 3, and references therein].

The off-stoichiometric Ni-Mn-In Heusler alloys exhibit a magnetostructural, field-induced metamagnetism at $\mathrm{H}$ $=\mathrm{H}_{\mathrm{M}}$, exchange bias, nonreciprocal effects in magnetization, large MCEs, and so on (see Refs. 2-6, and references therein). Large negative (normal) and positive magnetic entropy changes, attributed to the first-order transition (FOT)

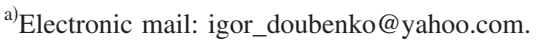

and second-order transition (SOT), have been observed in these materials near room temperature. ${ }^{2-4}$ The presence of both "normal" and "inverse" magnetic entropy changes near room temperature in the Heusler alloys (sometimes in the same material), has spurred the development of a refrigeration cycle that exploits both types of effects. ${ }^{7,8}$ It was reported that the $\Delta \mathrm{S}_{\mathrm{M}}$ and net refrigeration capacity, (after accounting for hysteresis loss) of $\mathrm{Ni}_{50} \mathrm{Mn}_{35} \mathrm{In}_{15}$ in the vicinity of the FOT and SOT were, respectively, $35 \mathrm{~J} \mathrm{~kg}^{-1} \mathrm{~K}^{-1}, 57$ $\mathrm{J} / \mathrm{kg}$ and $-5.7 \mathrm{~J} \mathrm{~kg}^{-1} \mathrm{~K}^{-1}, 123 \mathrm{~J} / \mathrm{kg}$ for $\Delta \mathrm{H}=5 \mathrm{~T} .{ }^{9}$ It has been also shown that the MCE of the In-based Heusler alloys are extremely sensitive to elemental substitution and stoichiometric variations. One example is the Si-doped $\mathrm{Ni}-\mathrm{Mn}-\mathrm{In}$ system, $\mathrm{Ni}_{50} \mathrm{Mn}_{35} \mathrm{In}_{15-\mathrm{x}} \mathrm{Si}_{\mathrm{x}}(1 \leq \mathrm{x} \leq 5)$. In this case, it was found that the Si doping resulted in a 300\% enhancement (for $\mathrm{x}=3$ ) of the maximum inverse magnetic entropy change to a value of $\Delta \mathrm{S}_{\mathrm{M}}=(+) 124 \mathrm{~J} \mathrm{Kg}^{-1} \mathrm{~K}^{-1}$ for a field change of $5 \mathrm{~T}$. The normal (negative) magnetic entropy change that occurs at the SOT spans a large temperature range (240-290 K). ${ }^{3,8,10}$ The adiabatic change in temperature, $\Delta \mathrm{T}_{\mathrm{ad}}$, has been studied for off-stoichiometric Heusler alloys in Refs. 11-13. It was found that $\Delta \mathrm{T}_{\mathrm{ad}}$ at $\mathrm{T}_{\mathrm{M}}$ is about $-3 \mathrm{~K}$ for $\Delta \mathrm{H}$ $=50 \mathrm{kOe}$ for $\mathrm{Ni}_{50} \mathrm{Mn}_{34} \mathrm{In}_{16}$ and $\mathrm{Ni}_{50} \mathrm{Mn}_{34} \mathrm{In}_{14} \mathrm{Ga}_{2}$. The $\Delta \mathrm{T}_{\text {ad }}$ -0.01 and $0.02 \mathrm{~K}$ for $\Delta \mathrm{H} \sim 0.1 \mathrm{~T}$ has been reported in vicinity of $\mathrm{T}_{M}$ and $\mathrm{T}_{C}$, respectively, for $\mathrm{Mn}_{50} \mathrm{Ni}_{40} \mathrm{In}_{10}$. However, most studies have concentrated on the $\Delta \mathrm{S}_{\mathrm{M}}$ evaluation from isothermal magnetizations measurements. Therefore, the search for materials that show a large value in fieldinduced adiabatic temperature changes in the vicinity of firstand second-order phase transitions at relatively low fields is important from an application perspective.

In this letter, we report the results of direct (magnetocalorimetric) measurements of $\Delta \mathrm{T}_{\mathrm{ad}}$ in vicinity of the phase transitions of $\mathrm{Ni}_{50} \mathrm{Mn}_{35} \mathrm{In}_{15}$ and $\mathrm{Ni}_{50} \mathrm{Mn}_{35} \mathrm{In}_{14} \mathrm{Z}(\mathrm{Z}=\mathrm{Al}$ and $\mathrm{Ge}$ ) for applied magnetic field changes up to $1.8 \mathrm{~T}$. The maximum $\Delta \mathrm{T}_{\mathrm{ad}}$ of about -2 and $2 \mathrm{~K}$ were found for FOT and SOT at $\Delta \mathrm{H}=1.8 \mathrm{~T}$, respectively, for all samples under investigation. It was observed that the presence of $\mathrm{Z}$ atoms 


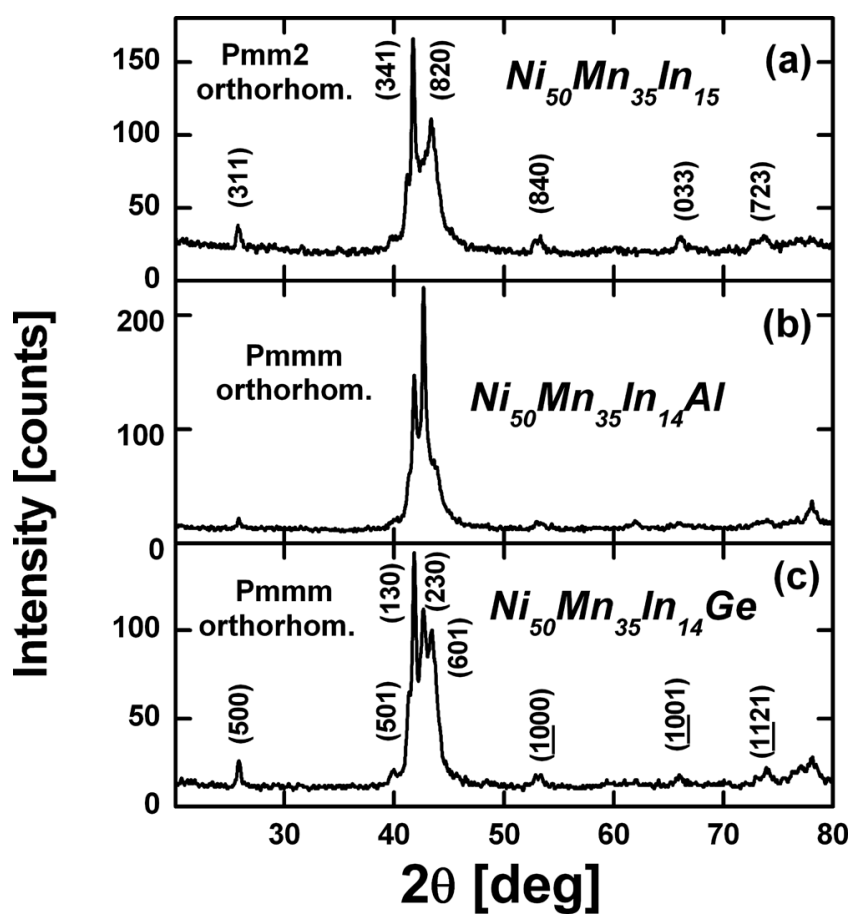

FIG. 1. Room temperature XRD patterns of $\mathrm{Ni}_{50} \mathrm{Mn}_{35} \mathrm{In}_{15}, \mathrm{Ni}_{50} \mathrm{Mn}_{35} \mathrm{In}_{14} \mathrm{Al}$, and $\mathrm{Ni}_{50} \mathrm{Mn}_{35} \mathrm{In}_{14} \mathrm{Ge}$.

$(\sim 1 \% \mathrm{Z})$ in In sites shifts the $\Delta \mathrm{T}_{\mathrm{ad}}$ maxima and slightly affects the value of $\Delta \mathrm{T}_{\text {ad }}$ of $\mathrm{Ni}_{50} \mathrm{Mn}_{35} \mathrm{In}_{15}$.

The samples were prepared by conventional arc-melting of high purity metal components in an argon atmosphere, followed by annealing at $850{ }^{\circ} \mathrm{C}$ for $24 \mathrm{~h}$ in vacuum $\left(10^{-4}\right.$ torr). The phase purity of the samples has been tested by $\mathrm{x}$-ray powder diffraction at room temperature using $\mathrm{Cu} K \alpha$ radiation. Direct temperature changes, $\Delta \mathrm{T}_{\mathrm{ad}}$, have been obtained with an adiabatic magnetocalorimeter in a temperature range of $250-350 \mathrm{~K}$, and in magnetic fields up to $1.8 \mathrm{~T}$. The external magnetic fields have been ramped at a rate of up to $2 \mathrm{~T} / \mathrm{s}$ during $\Delta \mathrm{T}_{\mathrm{AD}}$ measurements. For MCE measurements the samples have been cut into two plates of similar dimensions (about $3 \times 2 \times 1 \mathrm{~mm}^{3}$ ). The final adjustment of the sample mass has been done using an analytical balance with $10^{-4} \mathrm{~g}$ accuracy. Magnetization studies have been done using a vibrating sample magnetometer (Lake Shore VSM 7400 System) in a temperature interval of 80$400 \mathrm{~K}$, and in fields up to $1.8 \mathrm{~T}$. All measurements were carried out during heating after the samples were cooled from 400 to $80 \mathrm{~K}$ at zero magnetic field that correspond to the zero field cooled (ZFC) measurements.

Figures 1(a)-1(c) show room temperature x-ray diffraction (XRD) patterns of the samples under investigation. The crystal structures of the $\mathrm{Ni}_{50} \mathrm{Mn}_{35} \mathrm{In}_{15}$ and $\mathrm{Ni}_{50} \mathrm{Mn}_{35} \mathrm{In}_{14} \mathrm{Z}$ $(\mathrm{Z}=\mathrm{Al}$ and $\mathrm{Ge})$ have been determined (Refs. 7 and 9) as martensitic orthorhombic Pmm2 and Pmmm. The M(T) curves of all samples are very similar and can be characterized by three phase transition temperatures; $\mathrm{T}_{\mathrm{CM}}, \mathrm{T}_{\mathrm{A}}$, and $\mathrm{T}_{\mathrm{C}}$. Ferromagnetic type magnetization curves were observed in the $\mathrm{T}<\mathrm{T}_{\mathrm{CM}}$ and $\mathrm{T}_{\mathrm{A}}<\mathrm{T}<\mathrm{T}_{\mathrm{C}}$ intervals, and paramagnetic behavior was observed above $\mathrm{T}_{\mathrm{C}}$. The sharp change in magnetization at $\mathrm{T}_{\mathrm{A}}$ is associated with a martensitic transition from the magnetic state characterized by low magnetic moment (antiferromagnetic or paramagnetic state) to a ferromagnetic AP. The change in the ZFC magnetization in the low-

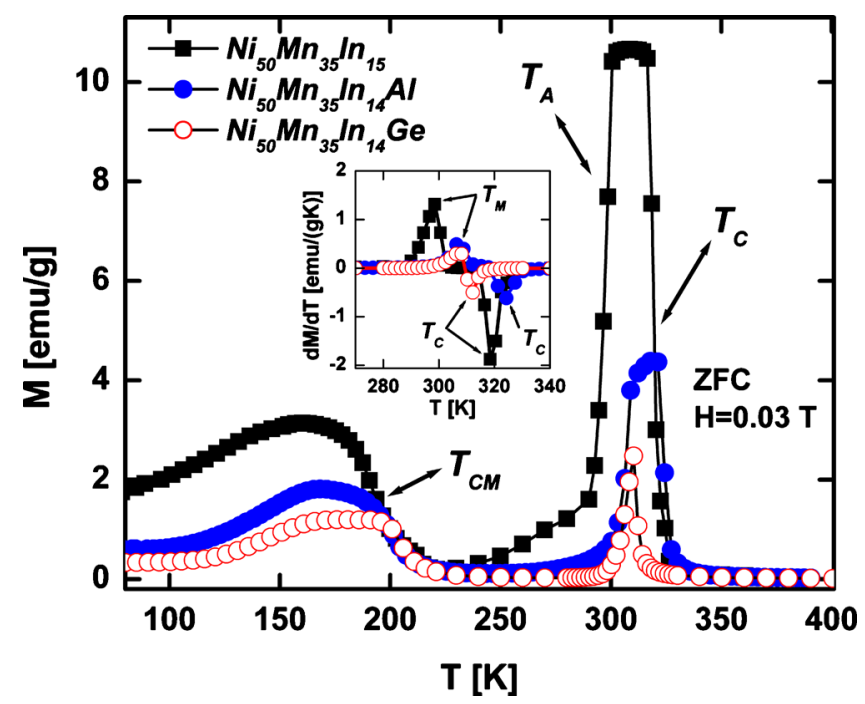

FIG. 2. (Color online) ZFC magnetization curves $M(T)$ for $\mathrm{Ni}_{50} \mathrm{Mn}_{35} \mathrm{In}_{15}$, $\mathrm{Ni}_{50} \mathrm{Mn}_{35} \mathrm{In}_{14} \mathrm{Al}$, and $\mathrm{Ni}_{50} \mathrm{Mn}_{35} \mathrm{In}_{14} \mathrm{Ge}$ Heusler alloys, obtained at $\mathrm{H}$ $=0.03 \mathrm{~T}$. Inset: $\mathrm{dM} / \mathrm{dT}$ curves in vicinity of $\mathrm{T}_{\mathrm{A}}$ and $\mathrm{T}_{\mathrm{C}}$

temperature region $\left(\mathrm{T}<\mathrm{T}_{\mathrm{CM}}\right)$ is typical for many $\mathrm{Ni}-\mathrm{Mn}-\mathrm{In}$ based compounds, and is related to the magnetic heterogeneity that can result in exchange bias effects. 3,9

Negative and positive changes in sample temperature were found, as expected, in the presence of external magnetic fields in the vicinity of the FOT and SOT, respectively (see Fig. 3). The magnitudes of $\Delta \mathrm{T}_{\mathrm{ad}}$ were found to be nearly similar (but opposite in sign) at both transitions. This behavior may be related to the similar nature of the transitions; a ferromagnetic to paramagnetic transition at $\mathrm{T}_{\mathrm{C}}$, and an inverse of that transition at $\mathrm{T}_{\mathrm{M}}$. The maxima of $\Delta \mathrm{T}_{\mathrm{ad}}$ are a linear function of applied field for the SOT but only slightly change at low magnetic fields $(0.3-1.0 \mathrm{~T})$ for the FOT [see inset of Fig. 3(a)] and increase nonlinearly at $\mathrm{H}>1.0 \mathrm{~T}$. The maxima of $\Delta \mathrm{T}_{\mathrm{ad}}$ are slightly smaller (by about 20\%) for $\mathrm{Ni}_{50} \mathrm{Mn}_{35} \mathrm{In}_{14} \mathrm{Ge}$ (compared to the other alloys) for both transitions. The FOT and SOT temperature ranges for this compound nearly overlap (see Fig. 2), and the ferromagnetic ordering in the AP is incomplete. Thus the magnetization of $\mathrm{Ni}_{50} \mathrm{Mn}_{35} \mathrm{In}_{14} \mathrm{Ge}$ above $\mathrm{T}_{\mathrm{M}}$ is smaller than that observed for $\mathrm{Ni}_{50} \mathrm{Mn}_{35} \mathrm{In}_{14} \mathrm{Al}$ and $\mathrm{Ni}_{50} \mathrm{Mn}_{35} \mathrm{In}_{15}$ (see Fig. 2), and this difference in magnetic order results in a decrease in $\Delta \mathrm{T}_{\mathrm{ad}}$.

The MCE at low magnetic fields is of particular importance from an application point of view. As one can see from Fig. 3(d), the changes in the sample temperatures remain rather large (about $1 \mathrm{~K}$ ) for both transitions for a relatively small magnetic field change of $1.0 \mathrm{~T}$. The relative cooling power (RCP), based on the adiabatic temperature change, has been estimated as $\operatorname{RCP}(\mathrm{T})=\Delta \mathrm{T}_{\mathrm{ad}}(\mathrm{T} ; \mathrm{H})^{*} \mathrm{dT}_{\mathrm{FWHM}}{ }^{14}$ $|\mathrm{RCP}|=23 \mathrm{~K}^{2}$ and $6 \mathrm{~K}^{2}$, for $\mathrm{Ni}_{50} \mathrm{Mn}_{35} \mathrm{In}_{15} ; 24 \mathrm{~K}^{2}$ and $7 \mathrm{~K}^{2}$, for $\mathrm{Ni}_{50} \mathrm{Mn}_{35} \mathrm{In}_{14} \mathrm{Al}$; and $5 \mathrm{~K}^{2}$ and $2 \mathrm{~K}^{2}$, for $\mathrm{Ni}_{50} \mathrm{Mn}_{35} \mathrm{In}_{14} \mathrm{Ge}$ as calculated in vicinity of $\mathrm{T}_{\mathrm{C}}$ and $\mathrm{T}_{\mathrm{M}}$, respectively, for $\Delta \mathrm{H}=1 \mathrm{~T}$, and Ref. 14 .

The maxima of $\Delta \mathrm{T}_{\mathrm{ad}}$ at the SOT are shifted to lower and higher temperature regions for $\mathrm{Ni}_{50} \mathrm{Mn}_{35} \mathrm{In}_{14} \mathrm{Ge}$ and $\mathrm{Ni}_{50} \mathrm{Mn}_{35} \mathrm{In}_{14} \mathrm{Al}$, respectively, compared to the parent compound. The temperature of the maximum of $\Delta \mathrm{T}_{\mathrm{ad}}$ at the FOT increases from 298 to $309 \mathrm{~K}$ for $\mathrm{Ni}_{50} \mathrm{Mn}_{35} \mathrm{In}_{15}$, following the changes in $\mathrm{T}_{\mathrm{M}}$. The observed results are in agreement with the estimation of $\Delta \mathrm{T}_{\mathrm{ad}}$ obtained in Ref. 15 from magnetization and specific heat capacity measurements of 

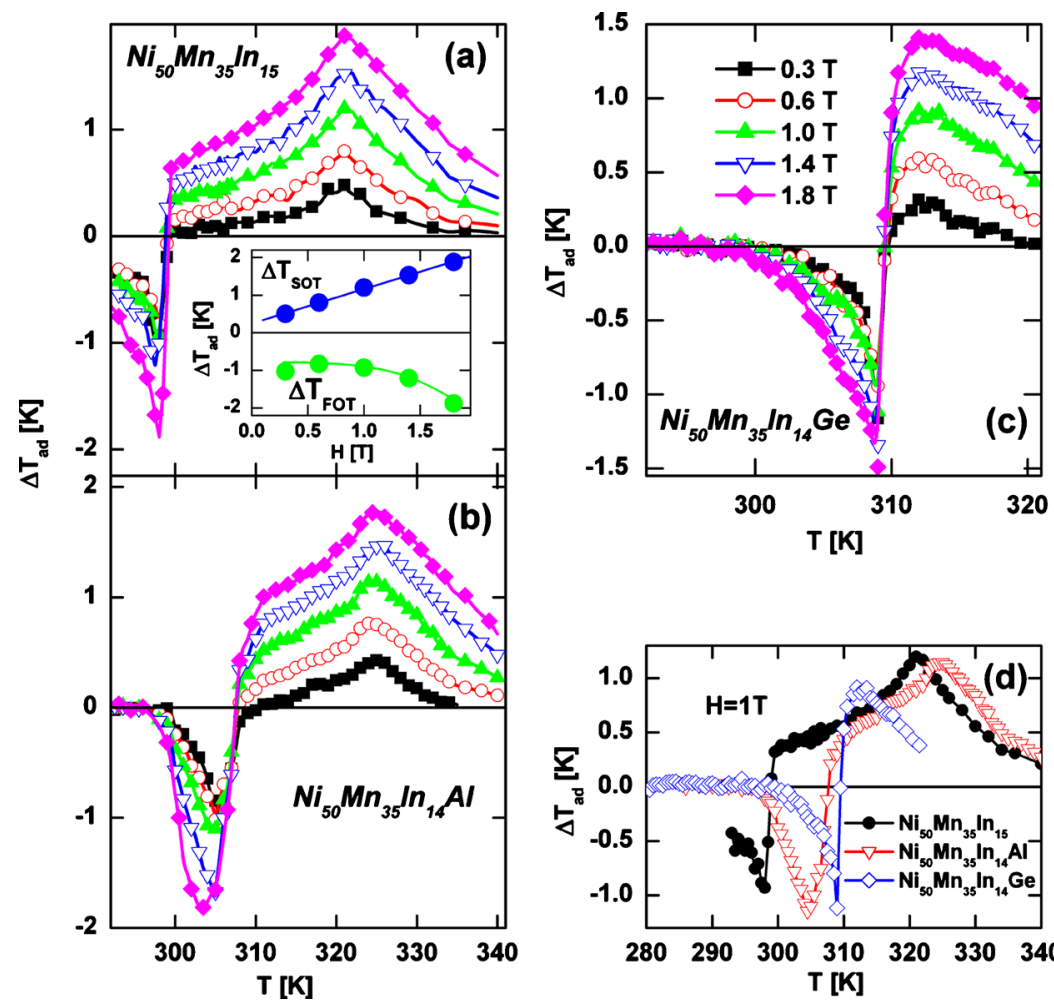

FIG. 3. (Color online) [(a)-(c)] The adiabatic temperature changes obtained at different magnetic fields [as it legend in (c)] and temperatures for $\mathrm{Ni}_{50} \mathrm{Mn}_{35} \mathrm{In}_{15}$, $\mathrm{Ni}_{50} \mathrm{Mn}_{35} \mathrm{In}_{14} \mathrm{Al}$, and $\mathrm{Ni}_{50} \mathrm{Mn}_{35} \mathrm{In}_{14} \mathrm{Ge}$. (d) Adiabatic temperature changes $\left(\Delta \mathrm{T}_{\mathrm{ad}}\right)$ as a function of temperature ( $\mathrm{T}$ ) for $\Delta \mathrm{H}=1 \mathrm{~T}$ for $\mathrm{Ni}_{50} \mathrm{Mn}_{35} \mathrm{In}_{15}$, $\mathrm{Ni}_{50} \mathrm{Mn}_{35} \mathrm{In}_{14} \mathrm{Al}$, and $\mathrm{Ni}_{50} \mathrm{Mn}_{35} \mathrm{In}_{14} \mathrm{Ge}$. Inset of Fig. 1(a), The maxima of $\Delta \mathrm{T}_{\text {ad }}$ as a function of applied $\mathrm{H}$. The results have been detected for magnetic fields ramped at

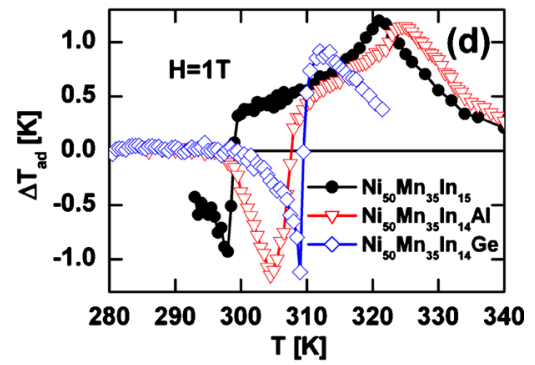
a rate of $2 \mathrm{~T} / \mathrm{s}$

$\mathrm{Ni}_{48} \mathrm{Co}_{2} \mathrm{Mn}_{35} \mathrm{In}_{15}$. The $\Delta \mathrm{T}_{\mathrm{ad}}$ observed for $\mathrm{Ni}_{50} \mathrm{Mn}_{35} \mathrm{In}_{15}$ and $\mathrm{Ni}_{50} \mathrm{Mn}_{35} \mathrm{In}_{14} \mathrm{Al}$ are larger than those reported for $\mathrm{Ni}_{50} \mathrm{Mn}_{34} \mathrm{In}_{16}$ in Refs. 11-13. This can be explained as a result of the difference in the magnetic states of these compounds just below their respective martensitic transition temperatures.

It is necessary to emphasize here that $\Delta \mathrm{T}_{\mathrm{ad}}$ is approximately the same magnitude at the FOT and SOT. However, $\Delta \mathrm{T}_{\mathrm{ad}}$ is free of hysteresis at the SOT, and there is no time dependence of $\Delta \mathrm{T}_{\mathrm{ad}}$ at the SOT [at least on the timescale of the most important applications, which typically operate at $1-10 \mathrm{~Hz}$ (Ref. 1)]. Our direct measurements of $\Delta \mathrm{T}_{\mathrm{ad}}$ with the rate of changing magnetic field of $0.05-2.0 \mathrm{~T} / \mathrm{s}$ did not reveal any time dependence of $\Delta \mathrm{T}_{\mathrm{ad}}$ at the SOT. In comparison with $\mathrm{Gd}$, which is (according Ref. 1) the most effective near room temperature, the $\mathrm{Ni}_{50} \mathrm{Mn}_{35} \mathrm{In}_{14} \mathrm{Z}(\mathrm{Z}=\mathrm{In}, \mathrm{Al}$, and Ge) Heusler alloys exhibit approximately the same MCE properties in vicinity of the SOT but they are much cheaper and do not contain chemically active components.

Using a magnetocalorimeter, we have directly measured the adiabatic temperature changes $\left(\Delta \mathrm{T}_{\mathrm{ad}}\right)$ of three $\mathrm{Ni}-\mathrm{Mn}-\mathrm{In}$ based Heusler alloys near their respective FOT (martensitic) and SOT (ferromagnetic). At the SOT, the magnitudes of $\Delta \mathrm{T}_{\mathrm{ad}}$ for these materials are a nearly linear function of applied field, whereas $\Delta \mathrm{T}_{\mathrm{ad}}$ at the FOT slightly changes at $\mathrm{H}$ $=0.3-1.0 \mathrm{~T}$. The largest negative $\Delta \mathrm{T}_{\mathrm{ad}}$ was observed in $\mathrm{Ni}_{50} \mathrm{Mn}_{35} \mathrm{In}_{15}$ to be about $-2 \mathrm{~K}$ at the martensitic transformation for a field change of $1.8 \mathrm{~T}$. The adiabatic temperature changes in about $1 \mathrm{~K}$ have been revealed for both, FOT and SOT, at a relativity small magnetic field change of $1 \mathrm{~T}$ for all of the studied compounds. The temperatures of the maxima of $\Delta \mathrm{T}_{\mathrm{ad}}$ were found to be tunable in the quaternary alloys $\mathrm{Ni}_{50} \mathrm{Mn}_{35} \mathrm{In}_{14} \mathrm{Z}$ by substituting $1 \%$ of $\mathrm{Z}=\mathrm{Al}$ and $\mathrm{Ge}$; the maxima could be shifted up to $11 \mathrm{~K}$ relative to the parent compound. These results, and the implied potential impact on magnetic refrigeration applications, provide an impetus for further research on these systems.

This work was supported by the Russian Foundation for Basic Research under Project No. 09-02-00309; by the Basque Foundation for Science; and by the Materials Science Division (BES), U.S. Department of Energy under Grant No. DE-FG02-06ER46291.

${ }^{1}$ K. A. Gschneidner, Jr., V. K. Pecharsky, and A. O. Tsokol, Rep. Prog. Phys. 68, 1479 (2005).

${ }^{2}$ T. Krenke, M. Acet, E. F. Wassermann, X. Moya, L. Mañosa, and A. Planes, Phys. Rev. B 73, 174413 (2006).

${ }^{3}$ I. Dubenko, M. Khan, A. K. Pathak, B. R. Gautam, S. Stadler, and N. Ali, J. Magn. Magn. Mater. 321, 754 (2009).

${ }^{4}$ T. Krenke, E. Duman, M. Acet, E. F. Wassermann, X. Moya, L. Mañosa, A. Planes, E. Suard, and B. Ouladdiaf, Phys. Rev. B 75, 104414 (2007),

${ }^{5}$ I. Dubenko, A. K. Pathak, S. Stadler, N. Ali, Y. Kovarskii, V. N. Prudnikov, N. S. Perov, and A. B. Granovsky, Phys. Rev. B 80, 092408 (2009).

${ }^{6}$ V. N. Prudnikov, A. P. Kazakov, I. S. Titov, N. S. Perov, A. B. Granovskii, I. S. Dubenko, A. K. Pathak, N. Ali, A. P. Zhukov, and J. Gonzales, JETP Lett. 92, 666 (2010).

${ }^{7}$ A. K. Pathak, M. Khan, I. Dubenko, S. Stadler, and N. Ali, Appl. Phys. Lett. 90, 262504 (2007).

${ }^{8}$ X. Zhang, B. Zhang, S. Yu, Z. Liu, W. Xu, G. Liu, J. Chen, Z. Cao, and G. Wu, Phys. Rev. B 76, 132403 (2007).

${ }^{9}$ A. K. Pathak, I. Dubenko, J. C. Mabon, S. Stadler, and N. Ali, J. Phys. D: Appl. Phys. 42, 045004 (2009).

${ }^{10}$ A. K. Pathak, I. Dubenko, S. Stadler, and N. Ali, J. Phys. D: Appl. Phys. 41, 202004 (2008).

${ }^{11}$ S. Aksoy, T. Krenke, M. Acet, E. F. Wassermann, X. Moya, L. Mañosa, and A. Planes, Appl. Phys. Lett. 91, 241916 (2007).

${ }^{12}$ A. M. Aliev, A. B. Batdalov, I. K. Kamilov, V. V. Koledov, V. G. Shavrov, V. D. Buchelnikov, J. García, V. M. Prida, and B. Hernando, Appl. Phys. Lett. 97, 212505 (2010).

${ }^{13}$ V. V. Khovaylo, K. P. Skokov, O. Gutfleisch, H. Miki, R. Kainuma, and T. Kanomata, Appl. Phys. Lett. 97, 052503 (2010).

${ }^{14}$ M.-H. Phan and S.-C. Yu, J. Magn. Magn. Mater. 308, 325 (2007).

${ }^{15}$ A. K. Pathak, I. Dubenko, Y. Xiong, P. W. Adams, S. Stadler, and N. Ali, J. Appl. Phys. 109, 07A916 (2011). 